\title{
A Turbine Based Combined Cycle Engine Inlet Model and Mode Transition Simulation Based on HiTECC Tool
}

Jeffrey T. Csank and Thomas J. Stueber

Glenn Research Center, Cleveland, Ohio 


\section{NASA STI Program . . . in Profile}

Since its founding, NASA has been dedicated to the advancement of aeronautics and space science. The NASA Scientific and Technical Information (STI) program plays a key part in helping NASA maintain this important role.

The NASA STI Program operates under the auspices of the Agency Chief Information Officer. It collects, organizes, provides for archiving, and disseminates NASA's STI. The NASA STI program provides access to the NASA Aeronautics and Space Database and its public interface, the NASA Technical Reports Server, thus providing one of the largest collections of aeronautical and space science STI in the world. Results are published in both non-NASA channels and by NASA in the NASA STI Report Series, which includes the following report types:

- TECHNICAL PUBLICATION. Reports of completed research or a major significant phase of research that present the results of NASA programs and include extensive data or theoretical analysis. Includes compilations of significant scientific and technical data and information deemed to be of continuing reference value. NASA counterpart of peer-reviewed formal professional papers but has less stringent limitations on manuscript length and extent of graphic presentations.

- TECHNICAL MEMORANDUM. Scientific and technical findings that are preliminary or of specialized interest, e.g., quick release reports, working papers, and bibliographies that contain minimal annotation. Does not contain extensive analysis.

- CONTRACTOR REPORT. Scientific and technical findings by NASA-sponsored contractors and grantees.
- CONFERENCE PUBLICATION. Collected papers from scientific and technical conferences, symposia, seminars, or other meetings sponsored or cosponsored by NASA.

- SPECIAL PUBLICATION. Scientific, technical, or historical information from NASA programs, projects, and missions, often concerned with subjects having substantial public interest.

- TECHNICAL TRANSLATION. Englishlanguage translations of foreign scientific and technical material pertinent to NASA's mission.

Specialized services also include creating custom thesauri, building customized databases, organizing and publishing research results.

For more information about the NASA STI program, see the following:

- Access the NASA STI program home page at http://www.sti.nasa.gov

- E-mail your question to help@sti.nasa.gov

- Fax your question to the NASA STI Information Desk at 443-757-5803

- Phone the NASA STI Information Desk at 443-757-5802

- Write to: STI Information Desk NASA Center for AeroSpace Information 7115 Standard Drive Hanover, MD 21076-1320 


\section{A Turbine Based Combined Cycle Engine Inlet Model and Mode Transition Simulation Based on HiTECC Tool}

Jeffrey T. Csank and Thomas J. Stueber

Glenn Research Center, Cleveland, Ohio

Prepared for the

48th Joint Propulsion Conference and Exhibit

cosponsored by the AIAA, ASME, SAE, and ASEE

Atlanta, Georgia, July 30-August 1, 2012

National Aeronautics and

Space Administration

Glenn Research Center

Cleveland, Ohio 44135 


\section{Acknowledgments}

The authors would like to thank Dr. James L. Pittman, the NASA Fundamental Aeronautics Program Hypersonic Project Manager for funding this work.

Trade names and trademarks are used in this report for identification only. Their usage does not constitute an official endorsement, either expressed or implied, by the National Aeronautics and Space Administration.

This work was sponsored by the Fundamental Aeronautics Program at the NASA Glenn Research Center.

Level of Review: This material has been technically reviewed by technical management.

Available from

NASA Center for Aerospace Information 7115 Standard Drive

Hanover, MD 21076-1320
National Technical Information Service 5301 Shawnee Road Alexandria, VA 22312

Available electronically at http://www.sti.nasa.gov 


\title{
A Turbine Based Combined Cycle Engine Inlet Model and Mode Transition Simulation Based on HiTECC Tool
}

\author{
Jeffrey T. Csank and Thomas J. Stueber \\ National Aeronautics and Space Administration \\ Glenn Research Center \\ Cleveland, Ohio 44135
}

\begin{abstract}
An inlet system is being tested to evaluate methodologies for a turbine based combined cycle propulsion system to perform a controlled inlet mode transition. Prior to wind tunnel based hardware testing of controlled mode transitions, simulation models are used to test, debug, and validate potential control algorithms. One candidate simulation package for this purpose is the High Mach Transient Engine Cycle Code (HiTECC). The HiTECC simulation package models the inlet system, propulsion systems, thermal energy, geometry, nozzle, and fuel systems. This paper discusses the modification and redesign of the simulation package and control system to represent the NASA large-scale inlet model for Combined Cycle Engine mode transition studies, mounted in NASA Glenn's 10- by 10-Foot Supersonic Wind Tunnel. This model will be used for designing and testing candidate control algorithms before implementation.
\end{abstract}

\section{Nomenclature}

$\begin{array}{ll}\text { AIP } & \text { Aerodynamic Interface Plane } \\ \text { AoA } & \text { Angle of Attack } \\ \text { CCE } & \text { Combined Cycle Engine } \\ \text { CCE-LIMX } & \text { Combined Cycle Engine Large scale Inlet for Mode transition eXperiments. } \\ \text { CDM } & \text { Control Design Models } \\ \text { CP } & \text { Cold Pipe } \\ \text { DMSJ } & \text { Dual-Mode Scram Jet } \\ \text { FAP } & \text { Fundamental Aeronautics Program } \\ \text { GN\&C } & \text { Guidance, Navigation, and Control } \\ \text { GRC } & \text { Glenn Research Center } \\ \text { HiTECC } & \text { High Mach Transient Engine Cycle Code } \\ \text { HSFP } & \text { High-Speed Flow Path } \\ \text { LAPIN } & \text { LArge Perturbation INlet simulation } \\ \text { LIMX } & \text { Large scale Inlet for Mode transition eXperiments } \\ \text { LSFP } & \text { Low-Speed Flow Path } \\ \text { NASA } & \text { National Aeronautics and Space Administration } \\ \text { PLA } & \text { Power Lever Angle } \\ \text { RALV } & \text { Reusable Airbreathing Launch Vehicle } \\ \text { RBCC } & \text { Rocket Based Combined Cycle } \\ \text { TBCC } & \text { Turbine Based Combined Cycle } \\ \text { TSTO } & \text { Two-Stage-To-Orbit } \\ \text { 10×10 SWT } & \text { 10- by 10-Foot Supersonic Wind Tunnel }\end{array}$

\subsection{Introduction}

The National Aeronautics and Space Administration (NASA) Fundamental Aeronautics Program (FAP) Hypersonic Project is concentrating on the development of tools and technologies to design and 
control reusable airbreathing launch vehicles (RALV). RALVs are intended to provide hypersonic flight through the Earth's atmosphere and create safe, routine, airline-type access to space. The RALV concept currently under study focuses on a two-stage-to-orbit (TSTO) vehicle that contains two separate sub vehicles each with its own propulsion system. The propulsion system for the first sub vehicle is responsible for horizontal take-off and acceleration of both vehicles to a hypersonic staging point. At the staging point, the two sub vehicles separate and each moves forward autonomously. The propulsion system being considered in this work is a Combined Cycle Engine (CCE) concept for the first sub vehicle, which incorporates an airbreathing turbine-based engine for take-off and acceleration to supersonic speeds, and a dual-mode scramjet (DMSJ) combustor for further acceleration to hypersonic speed. Together, these two stages are referred to as a Turbine Based Combined Cycle (TBCC) propulsion system. This TBCC propulsion system offers a split-flow inlet to provide airflow to an over-under engine configuration consisting of a turbine engine in the upper low-speed flow path (LSFP) and a DMSJ combustor in the lower high-speed flow path (HSFP). One of the challenges being addressed in this work is the act of transitioning primary thrust production from the LSFP turbine engine to the HSFP DMSJ, referred to as an inlet mode transition, while maintaining acceptable stability margin and performance.

To further understand the technology, obtain data to validate simulation models, and demonstrate a controlled mode transition, a large scale CCE inlet system has been designed, built, and mounted in the NASA Glenn Research Center (GRC) 10- by10-Foot Supersonic Wind Tunnel (10×10 SWT). A diagram of the CCE Large-scale Inlet for Mode transition eXperiments (CCE-LIMX) is shown mounted on a strut in the $10 \times 10$ SWT in Figure 1. The CCE-LIMX inlet system as illustrated in Figure 1 includes both a LSFP and a HSFP; the wind tunnel air flows from left to right. The variable geometry features of the CCE-LIMX, highlighted in the Figure 1 illustration, include a rotatable splitter, rotatable high-speed cowl, variable ramp, and overboard bypass doors. The following are other prominent features of the CCE-LIMX: the pivot pin located on the strut to control angle of attack (AoA), the pre-compression forebody plate, and the high-speed isolator. The distribution of compressed air coming off of the pre-compression forebody plate into the LSFP and HSFP is determined by the position of the splitter. The splitter can be rotated clockwise, as illustrated in Figure 1, towards the LSFP to close off, or counterclockwise, as illustrated in Figure1, towards the LSFP for full open. At LSFP full open, most of the compressed air off of the pre-compression forebody plate is directed into the LSFP. The upper surface of the splitter serves as a cowl for the LSFP, and the lower surface serves as a compression ramp for the HSFP. The CCE-LIMX also enables changing the cross sectional area of the LSFP throat by raising or lowering the variable ramp, which is significant since the cross sectional area of the LSFP is scheduled to decrease as vehicle speed increases. The air flow into the HSFP is also regulated by the rotation angle of the high-speed cowl.

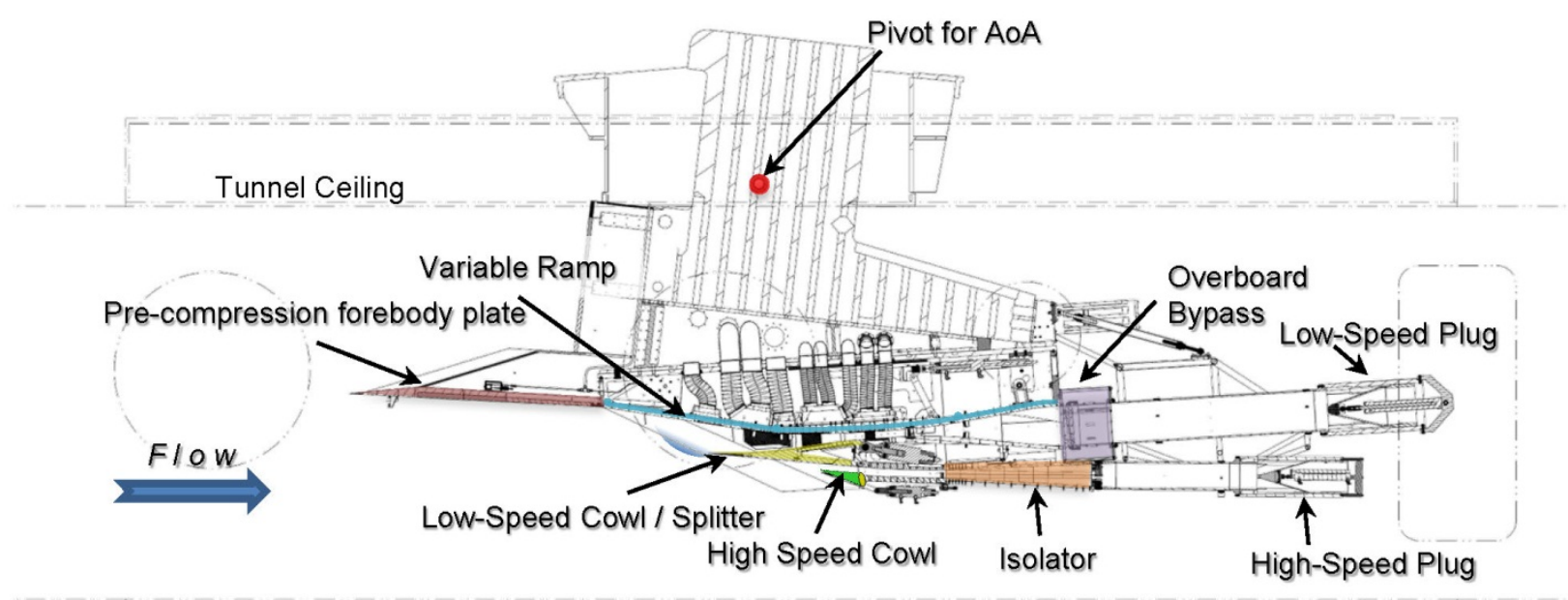

Tunnel Floor

Figure 1.-Diagram of the CCE-LIMX installed in GRC's 10×10 SWT. This figure illustrates the CCE-LIMX configured for inlet characterization and system identification experiments, with the variable geometry features highlighted. 
The CCE-LIMX is being evaluated in several phases to develop a unique TBCC database to assess and validate design and analysis tools and address operability, integration, and interaction issues for this class of advanced propulsion system (Ref. 1). For the first three phases of experiments, cold pipes with variable conical mass-flow plugs are mounted at the aerodynamic interface plane (AIP) of the LSFP and the HSFP. These cold pipe and plug assemblies will be used to create back pressure in the LSFP and HSFP similar to what is expected from turbine and DMSJ engines (Refs. 2, 3, 4, and 5).

The work in this report focuses on the LSFP. The LSFP mass-flow plug can be moved toward cold pipe close-off to create a subsonic volume that extends from the cold pipe exit up into the LSFP. The interface between the supersonic flow and the leading edge of the subsonic volume is known as the terminal shock or normal shock. The terminal shock is where the airflow nonlinearly changes from supersonic to subsonic. Careful placement of the LSFP mass-flow plug can position the terminal shock aft of the minimum cross sectional area - this is known as the started condition. Figure 2 shows a diagram of the LSFP in the started condition. The minimum cross sectional area, also known as the aerodynamic throat, is displayed in Figure 2 , while the volume downstream of the terminal shock is known as the diffuser. A well-controlled inlet will keep the normal shock within a tolerance window about a design point to meet performance specifications and stability margins. Inlet performance (air flow quality such as distortion and pressure ratio) is optimized with the normal shock located at the aerodynamic throat. However, this is a marginally stable position, meaning typical inlet disturbances can move the normal shock upstream of the throat and cause it to be ejected from the inlet - this is known as the unstarted condition. The unstarted condition results in a large and rapid reduction in air mass-flow to and pressure at the engine-inlet interface, and thus results in a thrust loss along with increased drag. Therefore, inlet operating points are specified to include stability margins that are set to prevent diffuser noise and potential disturbances from unstarting the inlet.

The purpose of the CCE-LIMX experiments is to develop tools and procedures that can be used to investigate and develop mode transition methods for a TBCC inlet system (Ref. 6). The series of experiments with the CCE-LIMX are designed to support the development of these tools and procedures and demonstrate their effectiveness. A successful mode transition in a TBCC is one that transitions from the turbine engine in the LSFP to the DMSJ in the HSFP while maintaining specified terminal shock position stability margins.

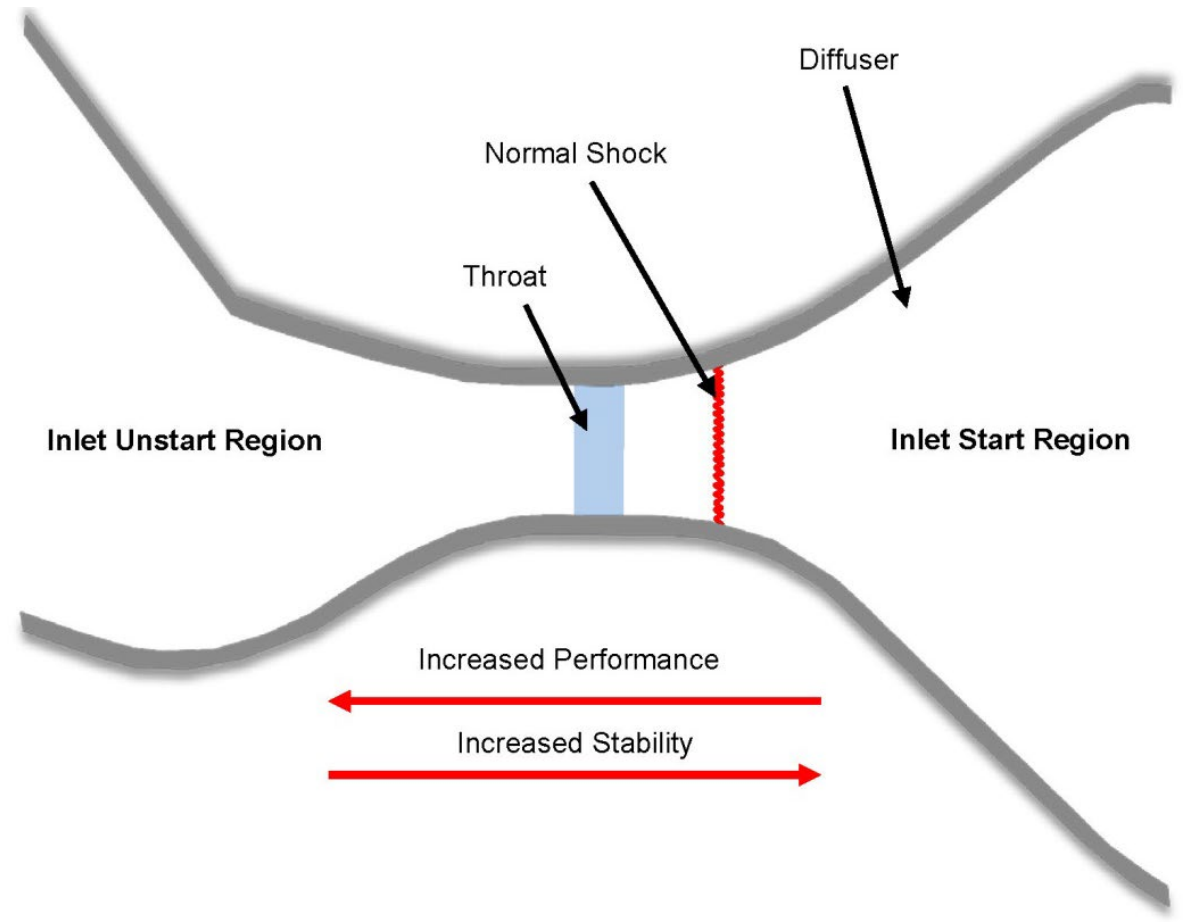

Figure 2.-Diagram showing the LSFP in a started condition, defined as the shock located aft of the throat. 
Potential inlet disturbances can be classified into the following three frequency ranges: high, moderately high, and low. A conventional turbine engine flow-path is designed with a diffuser volume that is capable of dampening high frequency disturbances, and a passive stability bleed system to reject moderately high frequency disturbances. Active control systems to regulate diffuser pressure by opening and closing diffuser bypass doors are needed to reject low frequency disturbances (Ref. 7). To aid the offline design of the active controllers, computational control design models (CDMs) are required. A CDM is a simplified version of either the physics-based simulation model or the physical system. The early CCE-LIMX test phases are designed to investigate the dynamic response of the diffuser (Ref. 8), and develop a CDM from the system to validate the CDM determined from physics-based computational models. The validated models will then be used for controls design, and the physics-based computational models will be used to demonstrate controlled mode transition in simulation prior to testing with the CCE-LIMX. The data contained in this paper are simulation results and have not been validated or compared against test data obtained from CCE-LIMX.

The Hypersonics propulsion controls team at GRC is developing a suite of tools and procedures, including simulation models. The tools and procedures are being designed to streamline experiment dynamic data analysis, inlet mode transition controls design, and controls evaluation (Ref. 9 and 10). One such tool is the High Mach Transient Engine Combined Cycle (HiTECC) (Ref. 10) code, developed by SPIRITECH Inc., which contains tools and models to simulate a complete TBCC propulsion system. The work reported on in this paper used the HiTECC simulation. HiTECC (Ref. 11) is a CCE simulation package featuring turbine and DMSJ propulsion system models, nozzle models, a heat transfer model, fuel flow models, hydraulics models, etc. The HiTECC tools were designed to be generic and modular to allow propulsion system changes to consider alternate inlet designs, DMSJs, or other turbine engine models. The HiTECC tools consist of the following four building blocks: a propulsion system (Ref. 12), a thermal management and fuel system model (Ref. 13), a hydraulics and kinematics model (Ref. 14), and a control system.

This paper focuses on the capabilities and the use of HiTECC as a control design tool for the CCE type propulsion systems such as one that may use an inlet system similar to the CCE-LIMX. Section 2.0 of this paper contains more information on HiTECC and modifications to the HiTECC simulation to match the CCE-LIMX design geometry. Section 3.0 proposes and shows HiTECC mode transition simulation results with simulated turbine and DMSJ engines. Section 4.0 of this paper discusses adding cold pipes and mass-flow plugs to HiTECC similar to the CCE-LIMX inlet as mounted in the wind tunnel. This paper concludes with a summary of the work.

\subsection{HiTECC Modifications for the CCE-LIMX Inlet}

The inlet system defined by the HiTECC propulsion system simulation is not representative of the actual CCE-LIMX geometry because the detailed mechanical design information was not available at the time the simulation was developed. However, since HiTECC was designed as a propulsion system simulation toolbox that employs the MathWorks, Inc. MATLAB software as a programming platform, the geometry, actuators, and control systems can be easily modified. This flexibility made the HiTECC simulation software readily modifiable to suitably represent the CCE-LIMX.

The HiTECC propulsion system includes an inlet geometry that can be defined using SimMechanics, a subset of Simscape (MathWorks, Inc.). The SimMechanics software accepts mechanical design documents created from a computer aided design (CAD) software package and converts them into a block diagram model suitably formatted for Simulink software using the MathWorks, Inc. Link software (Ref. 15). Installing SimMechanics Link into Pro/ENGINEER enables the Pro/ENGINEER software to export an Extensible Markup Language (XML) file based on the CAD drawings. The XML file can then be reformatted using the importxml function from the SimMechanics toolbox to conform to Simulink software-instructions and details are available from the MathWorks, Inc., website. This process was used to define the correct CCE-LIMX geometry for the HiTECC tools to simulate. The XML file can also be imported into an existing Simulink simulation. 
After entering the new CCE-LIMX geometry into HiTECC, the actuator set points and control systems needed to be modified as well. The original actuator set points defined the variable geometry alignment of the CCE-LIMX actuators for a flight mission that includes acceleration from low supersonic, through inlet mode transition event, and high supersonic Mach numbers. The variable geometry operating points were designed to provide the propulsion systems - turbine engine and DMSJ - with the required airflow throughout missions that include an inlet mode transition event. The original actuator controllers were designed to keep the actuators on point throughout the mission. The actuator control systems for the HiTECC simulation were unstable once the new geometry was installed. Therefore, to simulate inlet mode transition using the modified HiTECC, new operating points were defined and new actuator controllers were designed to keep the inlet system on schedule.

Comparisons of the modified HiTECC inlet geometry to the geometry of the actual CCE-LIMX are shown in Figure 3. The three left column traces in Figure 3 are actual hardware to simulation geometry comparisons at the Mach numbers of 4.0, 3.1, and 2.5. The three right column traces in Figure 3 illustrate the percent error between the actual hardware and simulated inlet geometries. Figure 3 indicates that the normalized area percent error between the modified HiTECC inlet model and the CCE-LIMX is within \pm 2 percent.
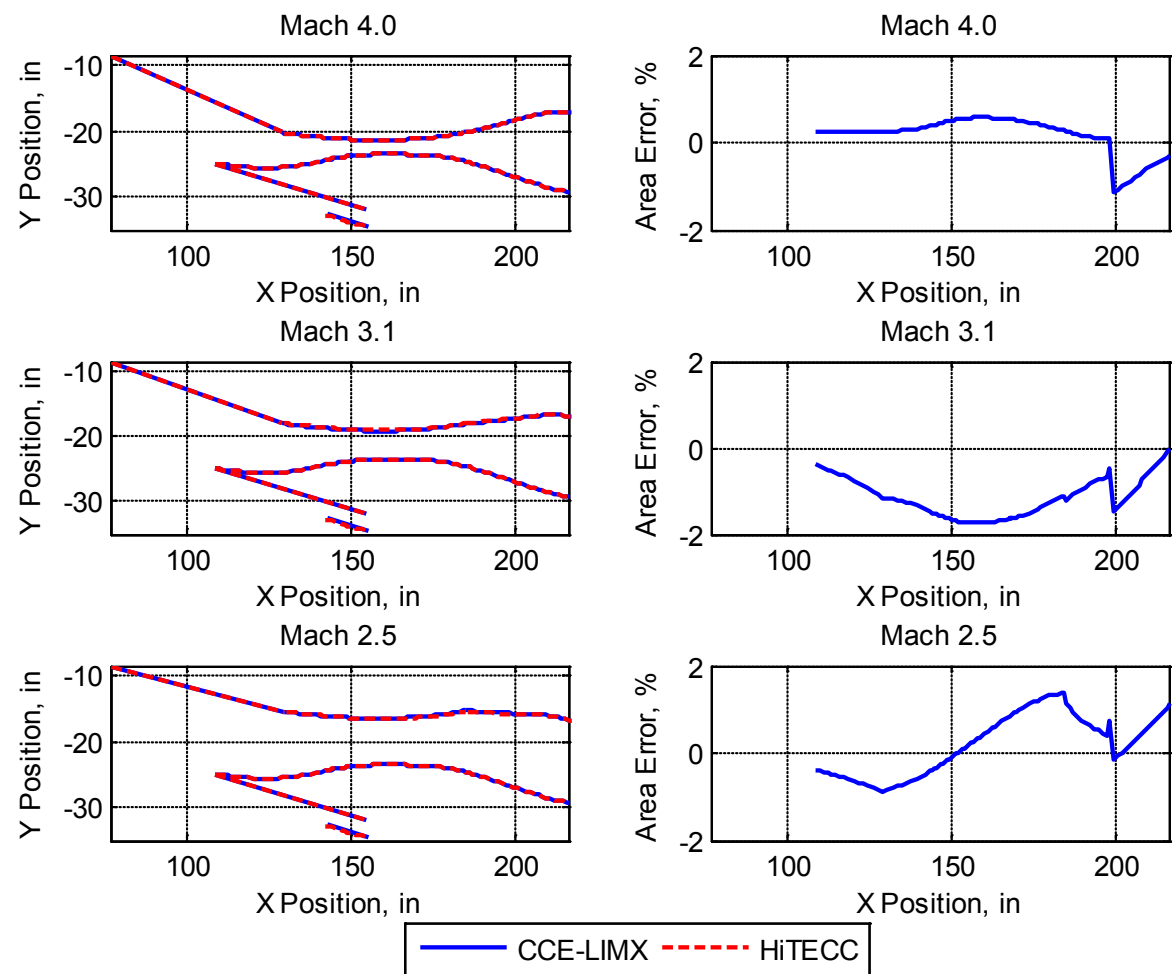

Figure 3.-Plots comparing the HiTECC geometry to the CCE-LIMX geometry at Mach numbers 4.0, 3.1, and 2.5. The left column compares the two geometries while the right column shows the percent difference in area between the HiTECC simulation and the CCE-LIMX hardware. The first row is at Mach 4.0, the second row is Mach 3.1, and the third row is at Mach 2.5. The area comparisons are only made for the LSFP that starts at the tip of the splitter (117 in.) and ends at the AIP (230 in.). 


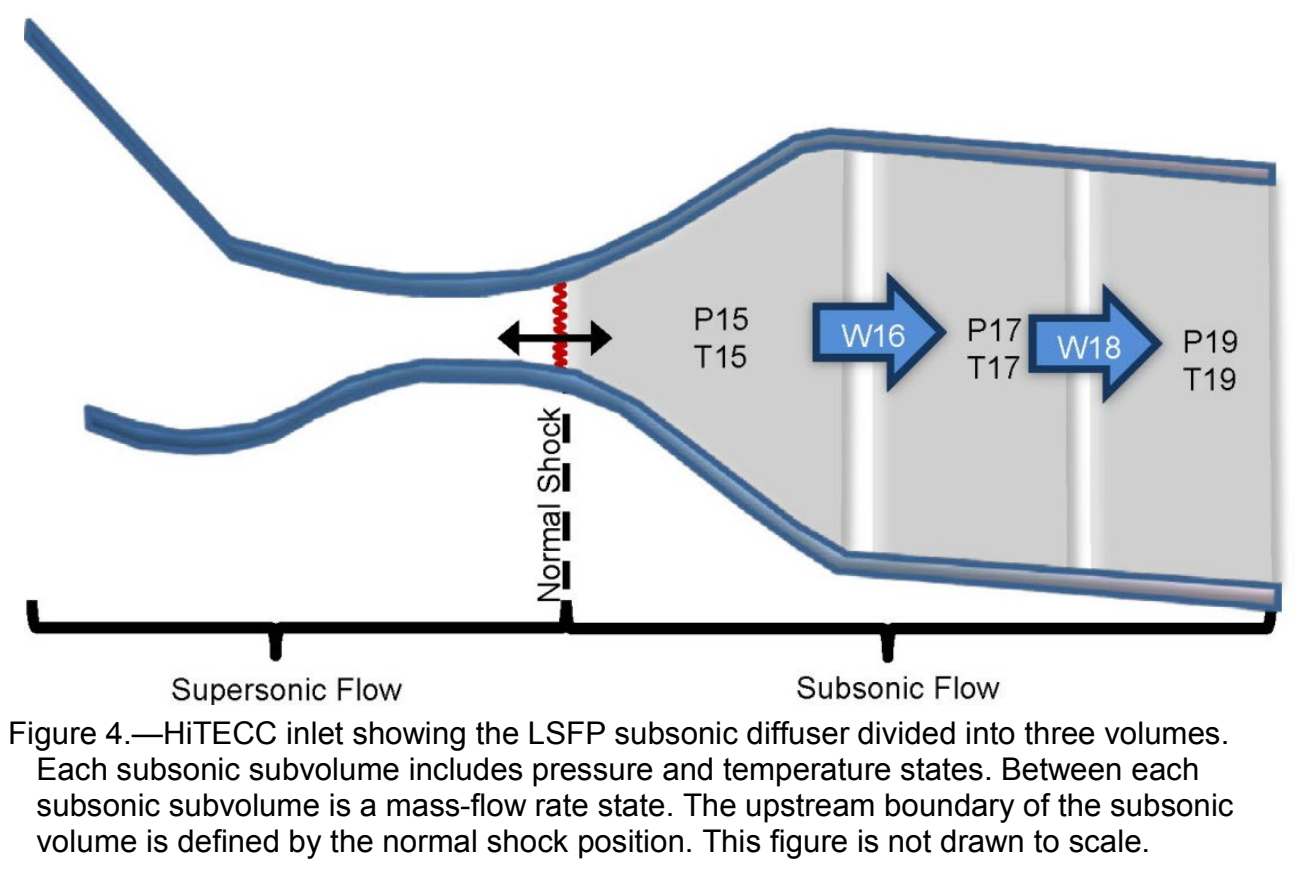

The HiTECC simulation includes a LSFP diffuser that is divided into three subsonic volumes, denoted Volume 15, Volume 17, and Volume 19, shown in Figure 4. The volume of Volume 15 is dependent on both the ramp position and normal shock position, which can change, while the volumes of Volume 17 and Volume 19 are defined by fixed geometry and remain constant. Each of these volumes includes pressure and temperature states. Furthermore, there are two flow states, W16 and W18. The subsonic flow from Volume 15 to Volume 17 is W16, and W18 is the subsonic flow from Volume 17 to Volume 19. The two flow states should be equal in steady state but will be different during transients. There is an additional state representing the normal shock position.

The HiTECC simulation is initiated with the simulation control integrators, or states, preset to steadystate operating values. If the error in the initial conditions is too large, the value of the integrator can ramp uncontrollably and crash the simulation. The initial conditions pertain to a given operating condition, or flight condition. The approach taken to establish the initial conditions for this simulation was to run the system from a previously known steady-state operating condition to a new operating condition. To use this approach, the original HiTECC geometry and control systems were implemented in parallel with the new updated geometry and control systems. The control system modifications included updating the actuator setpoints, modifying the inputs to the actuator setpoint generators, and retuning the controllers to meet the required bandwidth requirements. The parallel operation enabled each set of controllers to receive the same feedback signals. A time dependent switch was used to pass controller commands $(u)$ to the inlet - let $u_{1}$ be signals from the original controllers and $u_{2}$ be signals from the new controllers. The control signal for the inlet can be written as:

$$
u= \begin{cases}u_{1} & , t<5 \\ u_{1}\left(1-\frac{(t-5)}{10}\right)+u_{2} \frac{(t-5)}{10} & , 5 \leq t \leq 15 \\ u_{2} & , t>5\end{cases}
$$


From $t=0 \mathrm{~s}$ when the simulation started to $5 \mathrm{~s}$, the original geometry and control system operated the inlet model. From 5 to $15 \mathrm{~s}$, the control commands to the inlet from both the original system and the new system were combined to form a transitional command. Finally, the new geometry and control system were used exclusively as inputs to the inlet beyond $15 \mathrm{~s}$. This is a slow transition from one design to the other, but is capable of determining suitable initial conditions for the simulation by allowing the system values to settle at the end of the simulation. With the geometry updated for the CCE-LIMX inlet and initial conditions identified, the modified HiTECC simulation can be used to simulate a full mission profile that includes a mode transition event.

\subsection{Mode Transition}

During inlet mode transition, thrust production switches from 100 percent of the total vehicle thrust coming from the gas turbine engine, to a combination of thrust from both engines, to finally 100 percent thrust production from the DMSJ. This event occurs within a Mach number window that includes both turbine Mach number range and the DMSJ Mach number range. For this work, the gas turbine engine is assumed to be operable up to a speed of Mach 4.0 and the lower end of the DMSJ operability range is Mach 3.0, as was assumed in Reference 16, thus defining the inlet mode transition window. For this work, mode transition initiates at Mach 3.75, which was chosen to allow for a potential slight decrease in vehicle speed without losing operability of the DMSJ. Likewise, a slight increase in vehicle speed is allowable while mode transitioning without endangering the turbine engine.

The modified HiTECC software is used for simulating inlet mode transition as a vehicle flies a mission that includes accelerating from below Mach 3 to above Mach 4 The mission flight profile (vehicle altitude and Mach number) for this work is shown in the top plot of Figure 5. As illustrated in this plot, the vehicle Mach number and altitude are assumed to remain constant throughout the mode transition event. After mode transition, the vehicle will accelerate and increase altitude. The corresponding turbine engine and DMSJ power lever angles are shown in the bottom plot of Figure 5. Once the vehicle reaches Mach 3.75, which occurs at $t=1 \mathrm{~s}$, the afterburner will begin to shut down. The afterburner operates from a power lever angle (PLA) of 100 to 150. As the afterburner shuts down, the DMSJ increases thrust production. The actual mode transition, defined as the process of closing off flow through the LSFP, will begin once the afterburner is shut down at a PLA of 100 percent, and mode transition is completed when the fuel command to the turbine is shut down at a PLA of 10 percent.

For the simulated mode transition event, the thrust produced by each engine - the turbine engine and DMSJ-is shown in the top plot of Figure 6. The combined total thrust is shown in the bottom plot of Figure 6. During mode transition the propulsion system would ideally provide constant thrust to the vehicle. The bottom plot includes an assumed upper and lower thrust limit necessary to maintain the designated flight profile illustrated in Figure 5. In the top plot of Figure 6, the rapid thrust loss from the turbine engine at approximately $7 \mathrm{~s}$ is due to the engine turbine shutting down and the simulation lacking a windmilling model to accurately represent the transition from idle operation to complete shutdown, which would show a more gradual loss in thrust. This also leads to a momentary increase of total thrust from 7 to $7.25 \mathrm{~s}$ in the bottom plot of Figure 6, due to the rapid change in airflow for the LSFP to the HSFP, also due to the lack of a windmilling model.

Another consideration during the mode transition is the LSFP diffuser pressure and the location of the normal shock. The objective is to avoid an inlet unstart. For the simulation runs, the inlet will be considered unstarted if the diffuser pressure increases to a level such that the terminal shock reaches the aerodynamic throat, which for this inlet is at approximately 160 in. Figure 7 shows the LSFP diffuser pressure ratio, which is a ratio of the diffuser total pressure divided by the free-stream total pressure, and the location of the normal shock during the mode transition period. During mode transition, the pressure ratio is expected to decrease as the turbine spools down. Likewise, the normal shock is expected to move upstream. 

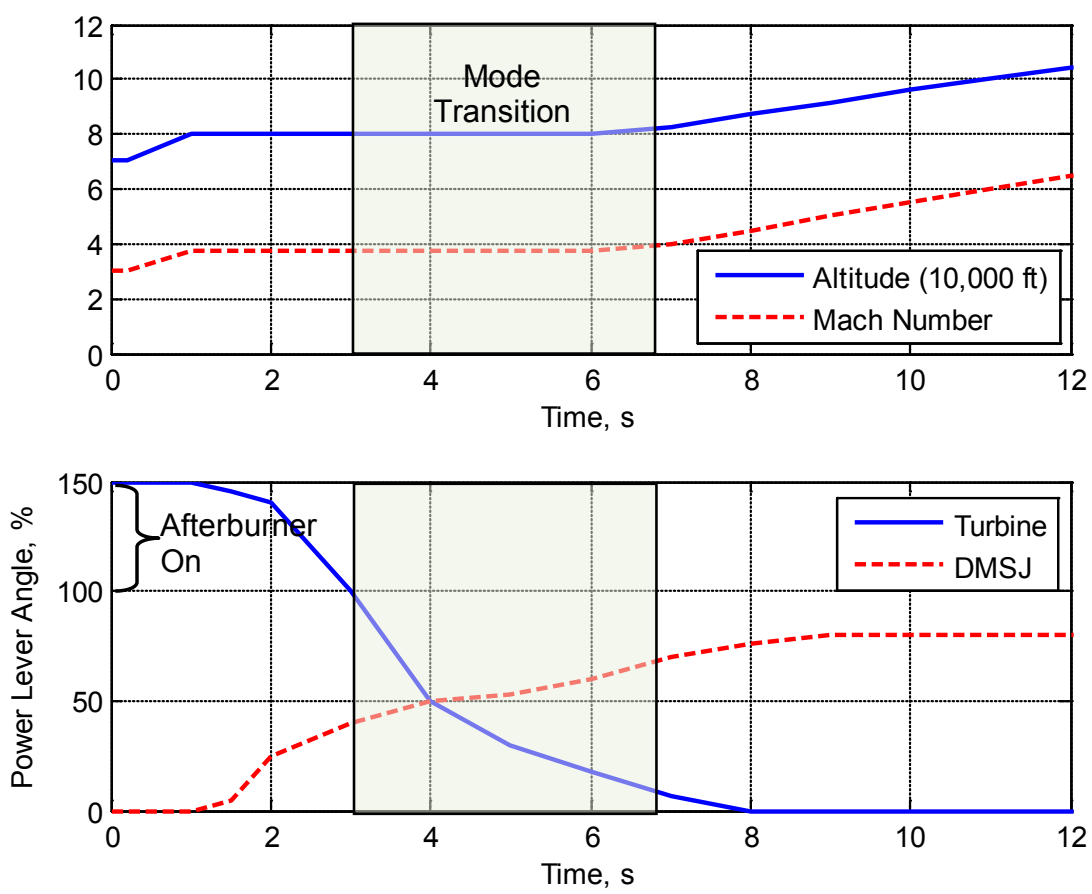

Figure 5.-A potential mode transition flight profile (top plot) and corresponding PLA commands for the turbine engine and DMSJ as determined using the modified HiTECC simulation. The mode transition is defined as the event of rotating the splitter towards low-speed flow path close off, thus redirecting all captured airflow to the DMSJ. The splitter will not rotate until the afterburner is turned off.
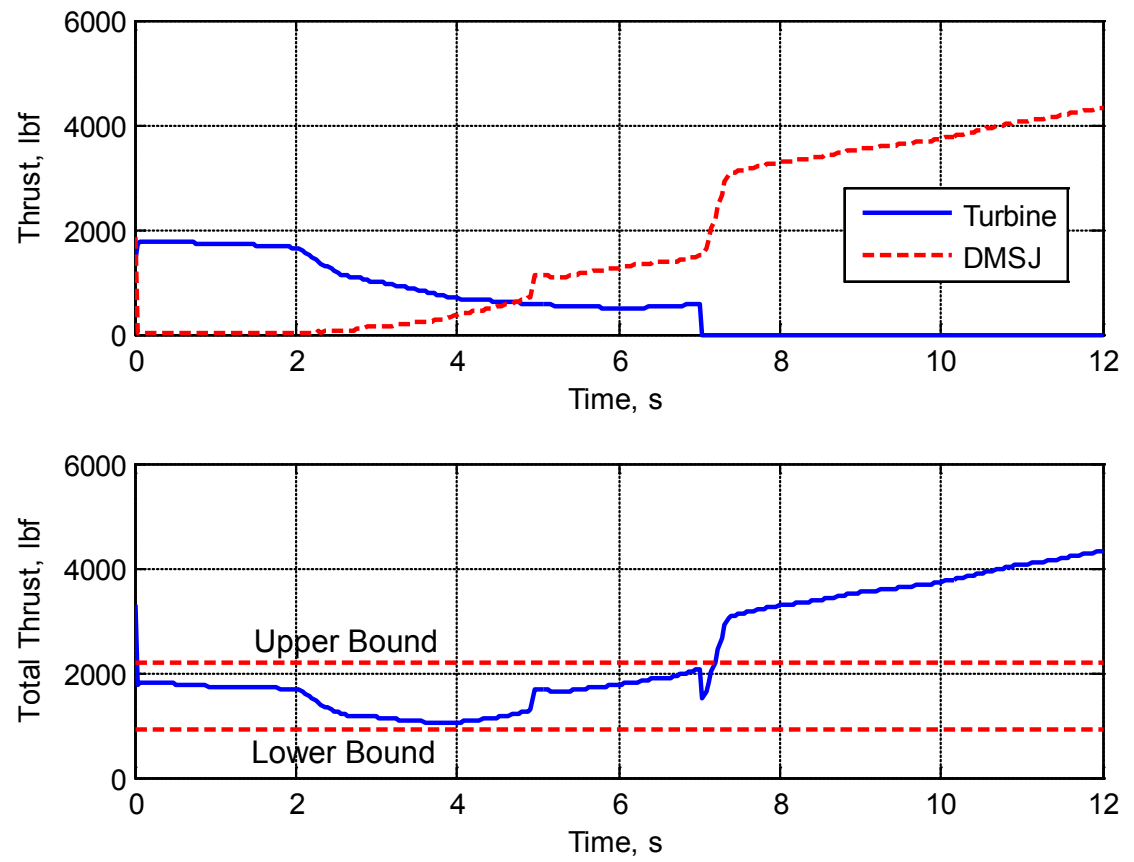

Figure 6.-Thrust produced by the turbine engine and DMSJ (top plot) and the total thrust produced by the TBCC (bottom plot). The rapid loss of the turbine thrust at approximately $7 \mathrm{~s}$ is due to the simulated turbine engine shutting down without a windmilling model representative of a turbine spooling down. In the bottom plot, hypothetical upper and lower bounds of thrust to maintain the flight profile are plotted in red. 

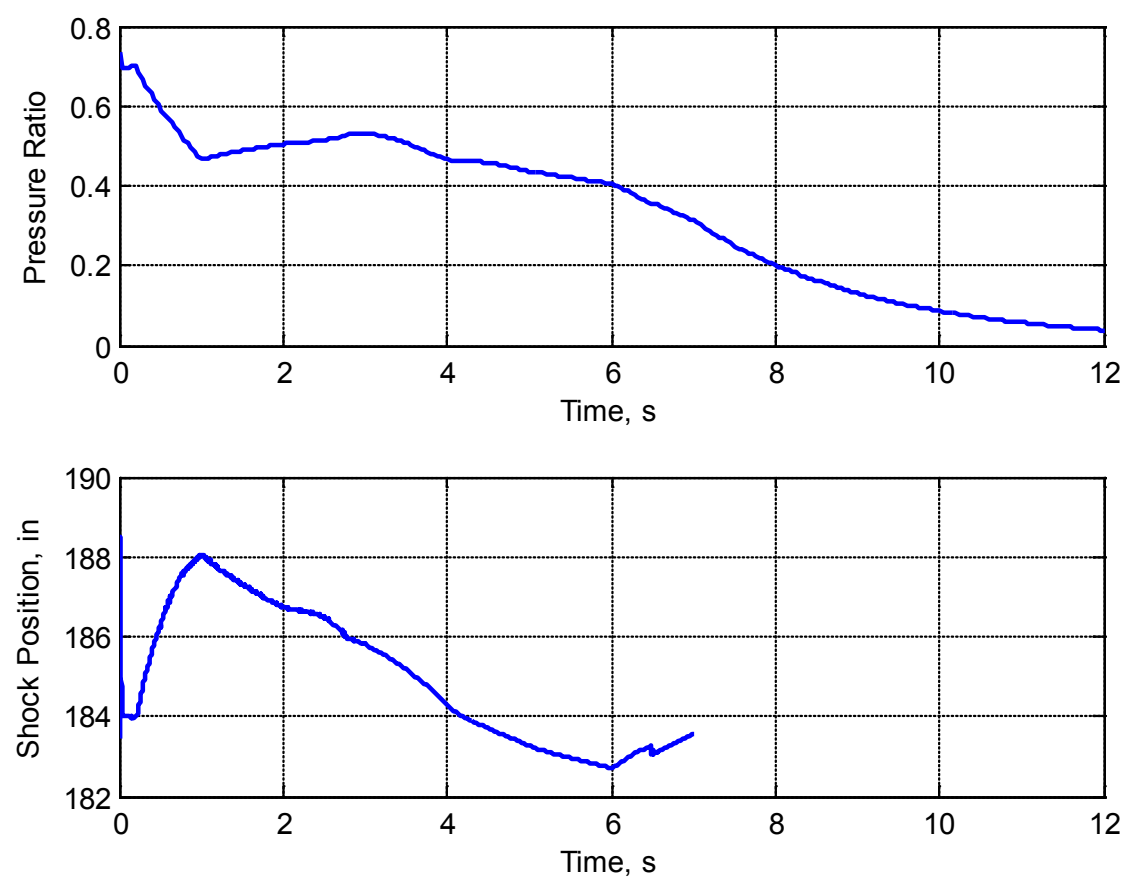

Figure 7.- The LSFP pressure ratio (top plot) and calculated shock position (bottom plot) through the mode transition event from 3 to $7 \mathrm{~s}$. At $t=7 \mathrm{~s}$, the LSFP is considered closed off and the normal shock does not exist as evident by the absence of data in the second plot. In this simulation, supersonic flow is free to flow through the LSFP to the bypass gates.

\subsection{HiTECC Wind Tunnel Model}

The CCE-LIMX as mounted in GRC's 10×10 SWT consists of the inlet and two cold pipes with mass-flow plugs in lieu of engines, as shown in Figure 1. The cold pipe and mass-flow plug systems will be used to create back pressure for the inlet, simulating the effect of the engines. The previously updated HiTECC simulation was modified to model the CCE-LIMX as mounted inside the $10 \times 10 \mathrm{SWT}$. This model, referred to as the HiTECC wind tunnel model, can serve as a computational test bed for test procedures and control algorithms. In addition, the HiTECC wind tunnel model can be tuned to match the data obtained from the wind tunnel experiments. This simulation does not include engine specific components such as the gas turbine engine, DMSJ, nozzle, fuel/thermal management systems, and associated control systems. Added to the HiTECC wind tunnel model is a simulated cold pipe (CP) and mass-flow plug system. This feature includes a linear actuator arm for inserting a mass-flow plug into the cold pipe to reduce the exit area of the cold pipe and increase back pressure in the inlet. A diagram of the cold pipe with a mass-flow plug is shown in Figure 8, and the relationship between the linear arm and cold pipe exit area is shown in Figure 9. The HiTECC model also is modified to include the additional volume of air, which is added to the system by the cold pipe. 


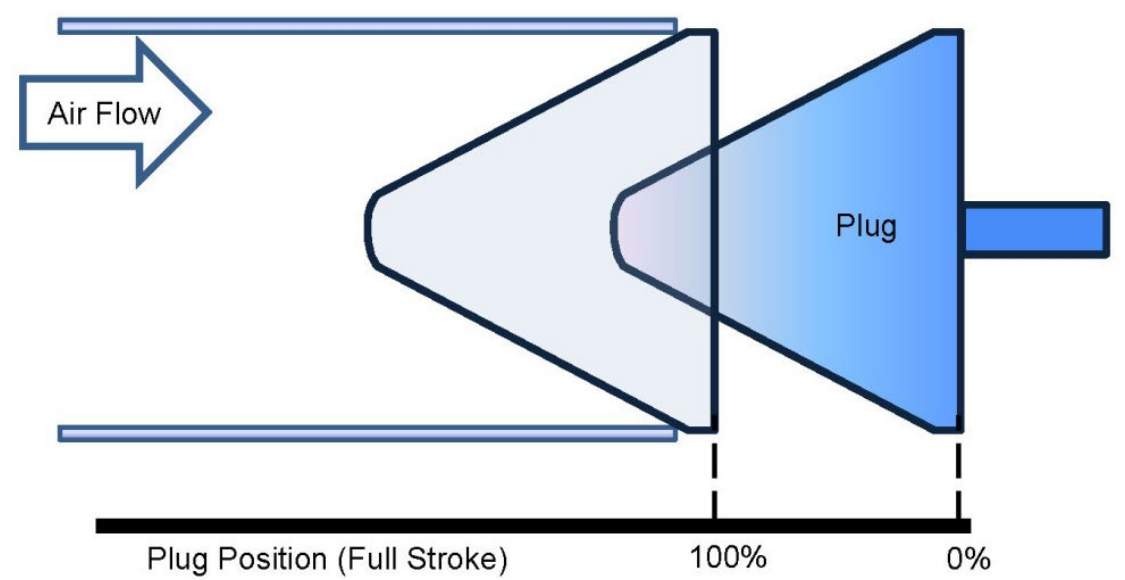

Figure 8.- Illustration of the cold pipe and mass-flow plug system. As the massflow plug is moved towards close-off, from 0 percent full stroke towards 100 percent full stroke, the exit cross sectional area of the cold pipe decreases.

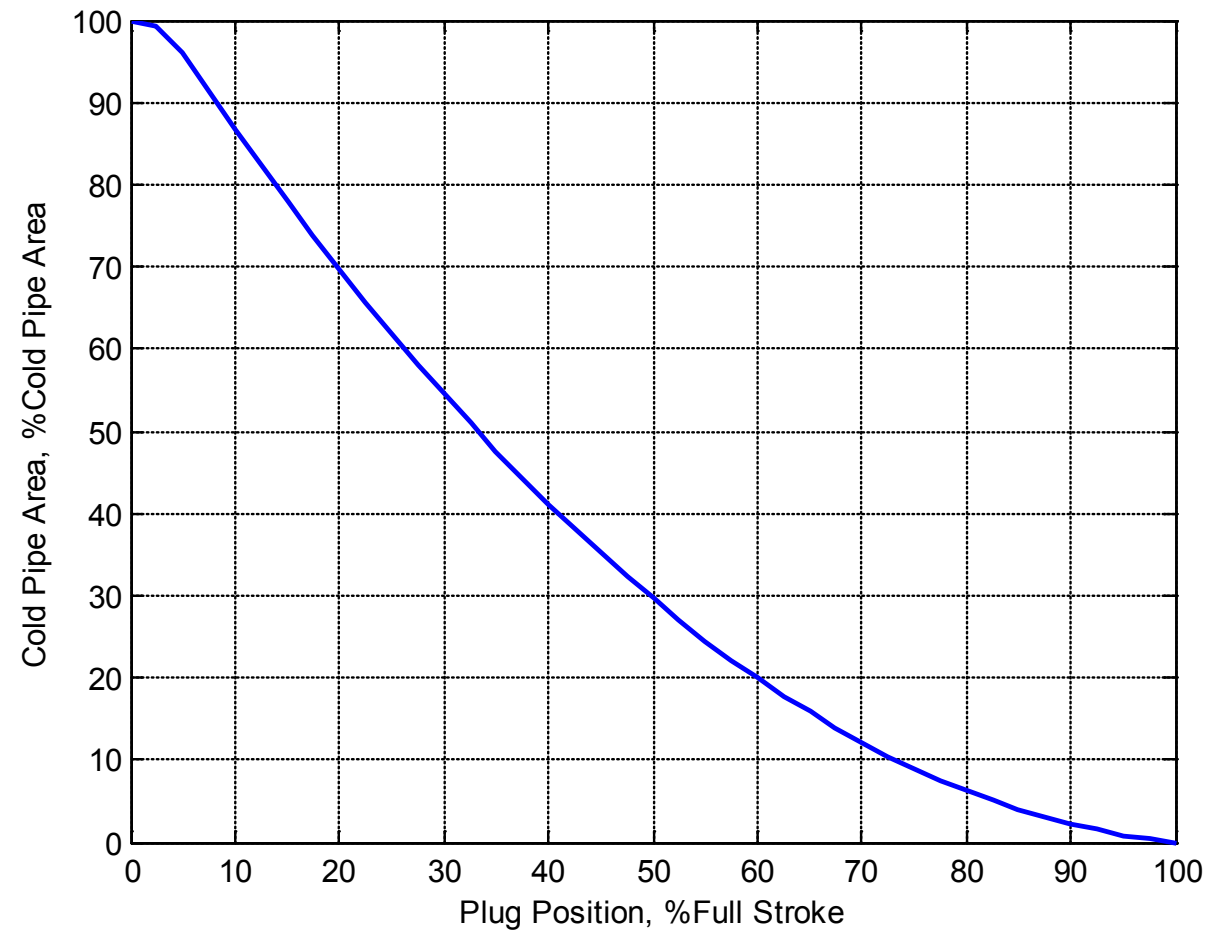

Figure 9.-Relationship between mass-flow plug position and cold pipe exit cross sectional area

Using the HiTECC wind tunnel model, a simulated mode transition event can be conducted at Mach 3.75. Simulation results comparing the inlet model with just a mass-flow plug added (No CP) and the system with the additional air volume of the cold pipe (CP), are shown in Figure 10. Figure 10 illustrates that the addition of the cold pipe volume to the simulation decreases the dynamic response of the inlet. For these simulations, throttle commands are replaced by a mass-flow plug position command. During mode transition, as the turbine is throttled down, the decreasing speed of the turbine engine will increase the diffuser back pressure. The diffuser back pressure can be similarly increased by moving the mass-flow plug in towards cold pipe close off, which simulates the decreasing speed of the turbine engine. At the $1.5 \mathrm{~s}$ point, the splitter is located to match the captured air flow requirements of an engine at idle. 

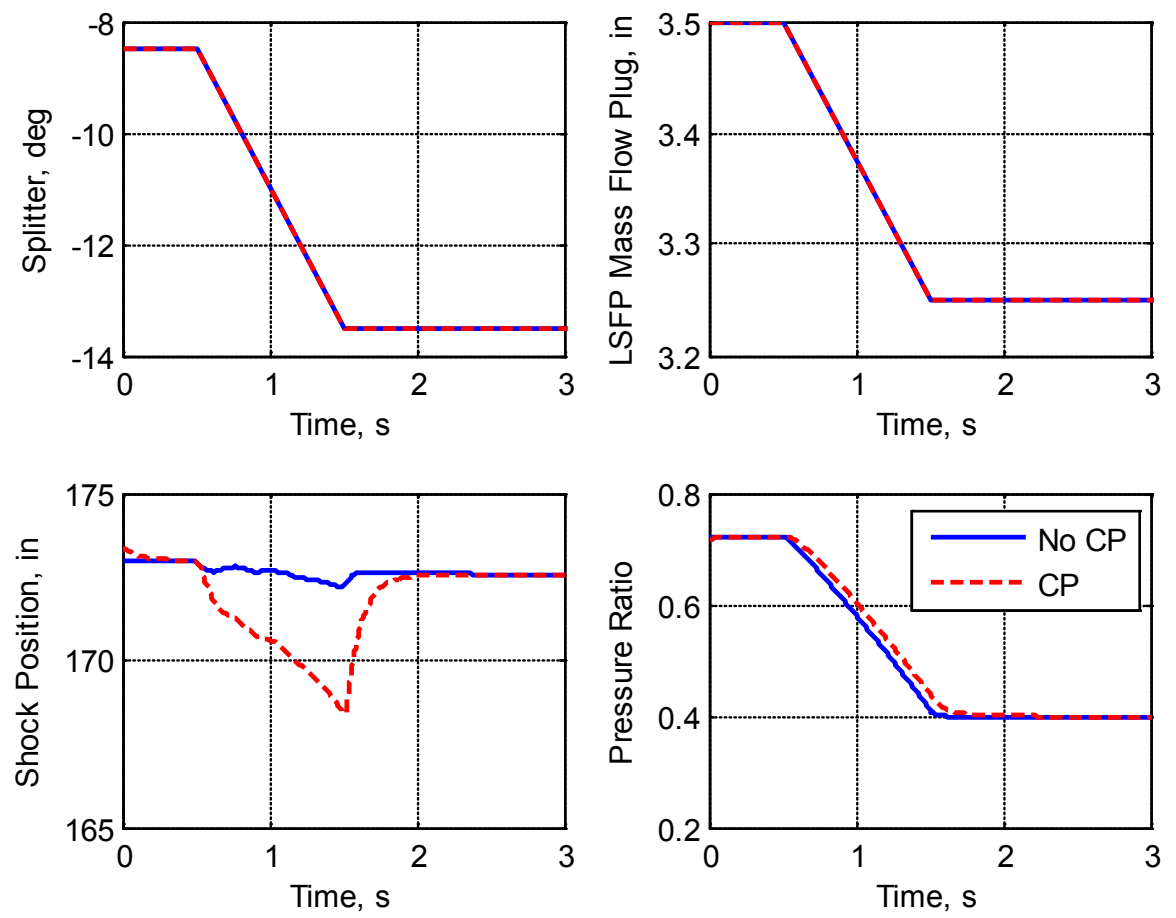

Figure 10.-LSFP Mass-flow plug and splitter positioning during simulated mode transition using the HiTECC wind tunnel model. The mass-flow plug position and splitter commands are shown in the top row. The bottom row illustrates the normal shock position and the pressure ratio during the 0.5 to $1.5 \mathrm{~s}$ mode transition period.

The propulsion system performance can be improved by operating the inlet with a higher pressure ratio, placing the normal shock closer to the aerodynamic throat. However, this reduces stability margin. The stability margin is based on a probability of an inlet unstart given potential disturbances in the inlet flow field. Therefore, to operate the inlet at a higher pressure ratio without decreasing stability margin requires a method to also decrease the probability of a potential disturbance that will push the terminal shock upstream of the aerodynamic throat at the higher pressure ratio. One proposed method is to employ an active control system to regulate the pressure ratio by controlling the opening and closing of bypass doors in the diffuser section, thereby controlling the position of the normal shock. Opening the bypass doors will decrease pressure ratio and the terminal shock position will move downstream; closing the bypass doors will increase pressure ratio and move the terminal shock position upstream and closer to the throat. Results of a simulation of the effect of opening the diffuser bypass doors are shown in Figure 11, for both the original system and the system with the additional cold pipe volume added. When the bypass door opens, the shock position location moves further from the throat, and the pressure ratio decreases. An active control system can be designed to automatically regulate the bypass doors based on the desired and current pressure ratio or current shock position. This simulation model will be used to develop CDMs suitable for controls studies and for testing candidate active inlet control systems prior to testing the controllers on actual CCE-LIMX hardware. Figure 11 again illustrates that the cold pipe volume slows the response of the system. 

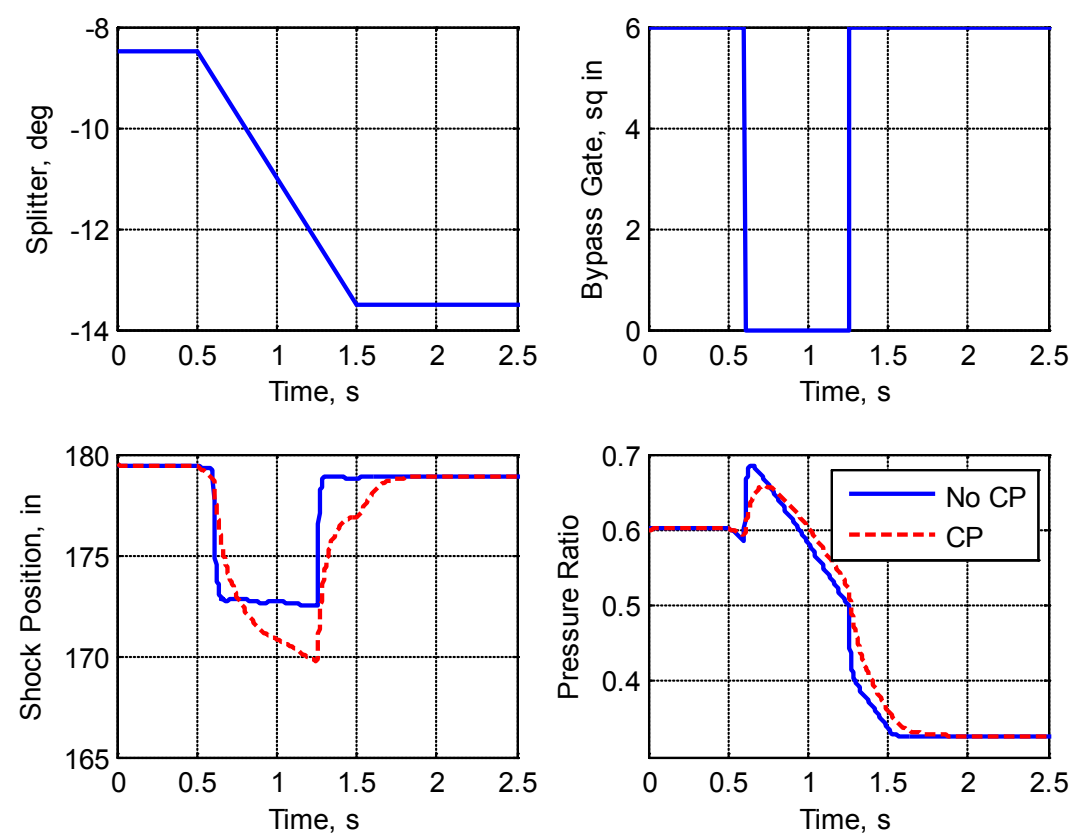

Figure 11.-The same mode transition schedule as illustrated in Figure 10 except a bypass door is actuated to show a change the diffuser pressure ratio and shock position during the mode transition period. For this set of simulations, the estimated shock position stays downstream from the $160 \mathrm{in}$. station.

\subsection{Summary}

In this paper, the High Mach Transient Engine Cycle Code (HiTECC) simulation package, created by SPIRITECH, Inc., has been modified to create two new models, both representative of the combined cycle engine large scale inlet for mode transition experiments (CCE-LIMX). The first model was updated to reflect the actual geometry of the CCE-LIMX, which included updating the actuator setpoints and controllers, and creating new initial conditions for the simulation. A mission profile demonstrating a successful full mode transition was simulated. This model will be used to evaluate the performance increase of a propulsion system with an active shock position control system employed, and the effect of the mode transition on the thrust produced by the propulsion system. The second model was designed to represent the CCE-LIMX as it is tested in the NASA Glenn Research Center Supersonic Wind Tunnel. To create the HiTECC wind tunnel model, the propulsion systems were replaced with cold pipes and massflow plugs, and the nozzle, fuel/thermal management systems, and associated control systems were removed. This model will be compared to and validated with test data. The validated model will be used to develop control design models suitable for controls studies and for testing candidate active inlet controllers prior to testing the controllers on actual CCE-LIMX hardware.

\section{References}

1. Saunders, J.D., Stueber, T.J., Thomas, S.R., Suder, K.L., Weir, L.J., and Sanders, B.W., "Testing of the NASA Hypersonic Project's Combined Cycle Engine Large Scale Inlet Mode Transition Experiment (CCE LIMX)," Joint Army-Navy-NASA-Air force (JANNAF), 32nd APS Joint Subcommittee Meeting, Arlington, VA, April 2011.

2. Musial, N.T., "Comparison of the Effect of a Turbojet Engine and Three Cold-Flow Configurations on the Stability of a Full-Scale Supersonic Inlet," NACA RM E56K23, January 1957. 
3. Bowditch, D.N. and Wilcox, F.A., "Dynamic Response of a Supersonic Diffuser to Bypass and Spike Oscillation," NASA TM X-10, August 1959.

4. Wasserbauer, J.F., "Dynamic Response of a Mach 2.5 Axisymmetric Inlet with Engine or Cold Pipe Supersonic Internal Area Contraction,” NASA TN D-5338, July 1969.

5. Baumbick, R.J., Wallbagen, R.E., Neiner, G.H., and Battertou, P.G., "Dynamic Response of Mach 2.5 Axisymmetric Inlet with 40 Percent Supersonic Internal Area Contraction,” NASA TM X-2833, July 1973.

6. Sanders, B.W., and Weir, L.J., "Aerodynamic Design of a Dual-Flow Mach 7 Hypersonic Inlet System for a Turbine-Based Combined-Cycle Hypersonic Propulsion System," NASA/CR—2008215214, June 2008.

7. Sanders, B.W. and Mitche, G.A., "Throat-Bypass Bleed Systems for Increasing the Stable Airflow Range of a Mach 2.5 Axisymmetric Inlet with 40-Percent Internal Contraction," NASA TM X-2779, May 1973.

8. Stueber, T.J., et al., "Dynamic Testing of the NASA Hypersonic Project Combined Cycle Engine Testbed for Mode Transition Experiments," NASA/TM-2011-217133, November 2011.

9. Soloway, D.I., Ouzts, P.J., Wolpert, D.H., Moerder, D.D., and Benivides, J.V., "The Role of Guidance, Navigation, and Control in Hypersonic Vehicle Multidisciplinary Design and Optimization," 16th AIAA/DLR/DGLR International Space Planes and Hypersonic Systems and Technology Conference, AIAA-2009-7329, 2009.

10. Stueber, T.J., Vrnak, D.R., Le, D.K., and Outzs, P.J., "Control Activity in Support of NASA Turbine Based Combined Cycle (TBCC) Research," Joint Army-Navy-NASA-Air-Force (JANNAF) Interagency Propulsion Committee, NASA/TM-2010-216109, La Jolla, CA, December 7-11, 2009.

11. Haid, D.A., and Gamble, E.J., "Integrated Turbine-Based Combined Cycle Dynamic Simulation Model," 58th Joint Army-Navy-NASA-Air-Force (JANNAF) Interagency Propulsion, Arlington, VA, April 18-22, 2011.

12. Gamble, E.J., Haid, D., D’Alessandro, S., and DeFrancesco, R., "Dual-Mode Scramjet Performance Model for TBCC Simulation," 45th AIAA/ASME/SAE/ASEE Joint Propulsion Conference and Exhibit, AIAA-2009-5298, Denver, CO, August 2-5, 2009.

13. Gamble, E.J. and Haid, D., "Thermal Management and Fuel System Model for TBCC Dynamic Simulation," AIAA/ASME/SAE/ASEE Joint Propulsion Conference and Exhibit, AIAA-2010-6642, Nashville, TN, July 25-28, 2010.

14. Gamble, E.J. and Haid, D., "Hydraulic and Kinematic System Model for TBCC Dynamic Simulation," 46th AIAA/ASME/SAE/ASEE Joint Propulsion Conference and Exhibit, AIAA-20106641, Nashville, TN, July 25-28, 2010.

15. http://www.MathWorks.com/help/toolbox/physmod/smlink/ug/brrdnfv.html, September 28, 2011.

16. Outzs, P.J., "Mode Transition Design Considerations for an Airbreathing Combined-Cycle Hypersonic Vehicle," 15th AIAA International Space Planes and Hypersonic Systems and Technologies Conference, AIAA-2008-2621, Dayton, OH, 28 April-1 May 2008. 


\begin{tabular}{|c|c|c|}
\hline \multicolumn{2}{|c|}{ REPORT DOCUMENTATION PAGE } & $\begin{array}{l}\text { Form Approved } \\
\text { OMB No. 0704-0188 }\end{array}$ \\
\hline \multicolumn{3}{|c|}{ 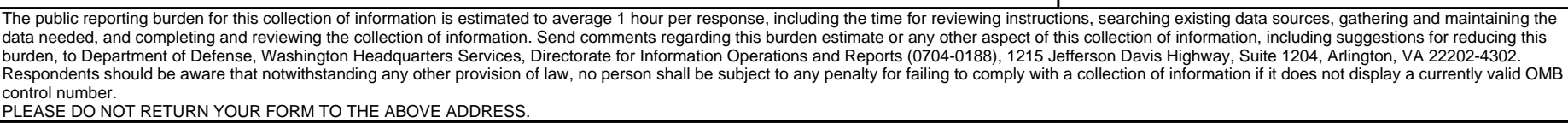 } \\
\hline $\begin{array}{l}\text { 1. REPORT DATE (DD-MM-YYYY) } \\
01-09-2012\end{array}$ & $\begin{array}{l}\text { 2. REPORT TYPE } \\
\text { Technical Memorandum }\end{array}$ & 3. DATES COVERED (From - To) \\
\hline \multirow{3}{*}{\multicolumn{2}{|c|}{$\begin{array}{l}\text { 4. TITLE AND SUBTITLE } \\
\text { A Turbine Based Combined Cycle Engine Inlet Model and Mode Transition Simulation } \\
\text { Based on HiTECC Tool }\end{array}$}} & 5a. CONTRACT NUMBER \\
\hline & & 5b. GRANT NUMBER \\
\hline & & 5c. PROGRAM ELEMENT NUMBER \\
\hline \multirow{3}{*}{\multicolumn{2}{|c|}{$\begin{array}{l}\text { 6. AUTHOR(S) } \\
\text { Csank, Jeffrey, T.; Stueber, Thomas, J. }\end{array}$}} & 5d. PROJECT NUMBER \\
\hline & & 5e. TASK NUMBER \\
\hline & & $\begin{array}{l}\text { 5f. WORK UNIT NUMBER } \\
\text { WBS 599489.02.07.03.07.11.02 }\end{array}$ \\
\hline \multicolumn{2}{|c|}{$\begin{array}{l}\text { 7. PERFORMING ORGANIZATION NAME(S) AND ADDRESS(ES) } \\
\text { National Aeronautics and Space Administration } \\
\text { John H. Glenn Research Center at Lewis Field } \\
\text { Cleveland, Ohio 44135-3191 }\end{array}$} & $\begin{array}{l}\text { 8. PERFORMING ORGANIZATION } \\
\text { REPORT NUMBER } \\
\text { E-18419 }\end{array}$ \\
\hline \multirow{2}{*}{\multicolumn{2}{|c|}{$\begin{array}{l}\text { 9. SPONSORING/MONITORING AGENCY NAME(S) AND ADDRESS(ES) } \\
\text { National Aeronautics and Space Administration } \\
\text { Washington, DC 20546-0001 }\end{array}$}} & $\begin{array}{l}\text { 10. SPONSORING/MONITOR'S } \\
\text { ACRONYM(S) } \\
\text { NASA }\end{array}$ \\
\hline & & $\begin{array}{l}\text { 11. SPONSORING/MONITORING } \\
\text { REPORT NUMBER } \\
\text { NASA/TM-2012-217714 }\end{array}$ \\
\hline \multicolumn{3}{|c|}{$\begin{array}{l}\text { 12. DISTRIBUTIONIAVAILABILITY STATEMENT } \\
\text { Unclassified-Unlimited } \\
\text { Subject Categories: } 07 \text { and } 63 \\
\text { Available electronically at http://WWw.sti.nasa.gov } \\
\text { This publication is available from the NASA Center for AeroSpace Information, 443-757-5802 }\end{array}$} \\
\hline
\end{tabular}

\section{SUPPLEMENTARY NOTES}

\section{ABSTRACT}

An inlet system is being tested to evaluate methodologies for a turbine based combined cycle propulsion system to perform a controlled inlet mode transition. Prior to wind tunnel based hardware testing of controlled mode transitions, simulation models are used to test, debug, and validate potential control algorithms. One candidate simulation package for this purpose is the High Mach Transient Engine Cycle Code (HiTECC). The HiTECC simulation package models the inlet system, propulsion systems, thermal energy, geometry, nozzle, and fuel systems. This paper discusses the modification and redesign of the simulation package and control system to represent the NASA large-scale inlet model for Combined Cycle Engine mode transition studies, mounted in NASA Glenn's 10- by 10-Foot Supersonic Wind Tunnel. This model will be used for designing and testing candidate control algorithms before implementation.

\section{SUBJECT TERMS}

Engine controls; Hypersonics

\begin{tabular}{|c|c|c|c|c|c|}
\hline \multicolumn{3}{|c|}{ 16. SECURITY CLASSIFICATION OF: } & \multirow{2}{*}{$\begin{array}{l}\text { 17. LIMITATION OF } \\
\text { ABSTRACT } \\
\text { UU }\end{array}$} & \multirow{2}{*}{$\begin{array}{l}\text { 18. NUMBER } \\
\text { OF } \\
\text { PAGES } \\
20\end{array}$} & \multirow{2}{*}{$\begin{array}{l}\text { 19a. NAME OF RESPONSIBLE PERSON } \\
\text { STI Help Desk (email:help@sti.nasa.gov) } \\
\text { 19b. TELEPHONE NUMBER (include area code) } \\
\text { 443-757-5802 }\end{array}$} \\
\hline $\begin{array}{l}\text { a. REPORT } \\
\text { U }\end{array}$ & $\begin{array}{l}\text { b. ABSTRACT } \\
\text { U }\end{array}$ & $\begin{array}{l}\text { c. THIS } \\
\text { PAGE } \\
\text { U }\end{array}$ & & & \\
\hline
\end{tabular}



